\title{
A View on Contemporaneity Through the Discourse of Postmodernism*
}

\author{
Olga Chistyakova \\ Faculty of Humanities and Social Sciences \\ Department of Social Philosophy \\ Peoples' Friendship University of Russia (RUDN University) \\ 6 Miklukho-Maklaya Street, Moscow, 117198, Russian Federation \\ E-mail: olgachis@yandex.ru
}

\begin{abstract}
The article discusses the basic principles of the social existence displayed as the signs of the postmodern world. The author analyses some philosophical concepts and teachings of the postmodernism (Z. Bauman, J. Baudrillard, J. Urry, A. Giddens) in their reflection of social problems of contemporaneity. The special attention the author devotes to the global tourism as one of the path for a personal identification in the modern world's diversity. Tourism is depicted in the context of the postmodernism as a relevant phenomenon uniting the multicultural world and partially solving certain social problems of the postmodernity.
\end{abstract}

Keywords-contemporaneity; modern communications; contemporary culture; postmodernism; institutionalization of tourism; social problem of postmodern society

\section{INTRODUCTION}

Philosophical comprehension of contemporaneity results naturally from objective realities and processes, that sped up dynamics, that characterize the societies, that have entered the postmodern era. The representatives of the postmodern philosophy suggest a new vision for the new era, trying to create analytical descriptions and interpretations, radically different from the preceding narratives of modernity. Above all are the problems of society, essentially changed communications, and possibilities for self-identity in a complex world of postmodernity.

\section{SIGNS OF POSTMODERNITY}

Reflections on our society, that we're all living in, are not optimistic. The preceding era of the "late" (Z. Bauman), or "radical" (A. Giddens), or "reflexive" (U. Beck) modernity formed and passed to our time such principles of existence as the fragmentation of the world and social order, atomization of social life, that are being replaced, according to J-F. Lyotard, by "language games". The culture of the contemporary society is characterized by "deterritorialization" of space and timelessness of social facts. A social fact is thus described in an obscure way - it's

*This paper was financially supported by the Ministry of Education and Science of the Russian Federation on the program to improve the competitiveness of Peoples' Friendship University (RUDN University) among the world's leading research and education centers in the 2016-2020. unclear, when and where it occurs. The aspects of inconsistency among the artifacts of culture and their representation in images, symbols, and signs are being built up gradually in the preceding society of modernity [1]. Modernity is preparing immanently the crisis of representation, as society lives in the copies of the copies as the "Xerox culture", in terms of J. Baudrillard.

In postmodern era, people live in "non-places", according to the British philosopher Z. Bauman. "Non-place" is a space devoid of meaning, identity (ethnic, religious, historical). This voidness was brought by globalization, which is gradually blurring the distinctions, uniqueness and brings in consistency. "Non-places", or "cities of nowhere", share some properties with public urbanized spaces, that are left uncivilized in the social and spiritual senses. Bauman writes, that such "non-places recognize the inevitability of the strangers" presence" [2; P. 111] and minimize all the individual features of people. He refers all the airports, highways, hotel rooms, etc. to such "non-places". In our opinion, modern cities, or other human settlements may also be classified as "non-places", as they don't allow people to feel themselves "at home", do not inject comfort and coziness, first of all, in cultural and moral senses. "Nonplaces" are inhospitable to modern individuals, as the epoch itself is described by certain "homelessness" and the abandonment of men. M. Buber expressed the idea that in the history of societies there are eras of "set up" and "homelessness", insecurity and "abandonment by God", when the acute feelings of loneliness, insecurity, personal catastrophe, the briefness of life are especially strongly felt.

It seems to us, that we live in an age of disorder when an individual is found in a situation of being "not at home" in a rapidly changing world with the accelerated flow of social time. Therefore, the feeling of being an eternal traveler and stranger (even in the city of your birth) is inherent to all people today. "Non-cities" or "non-places" are a kind of "empty spaces" in which individuals must somehow settle and adapt to the rules of the game (political, social, culturalidentification), that are being installed in addition to the mind and will of a modern individual. 


\section{III. "THE DISAPPEARANCE OF THE SOCIAL" AND DE- INSITUTIALIZATION OF THE PUBLIC STRUCTURES}

In the postmodern society, there is a blurring of previous social institutions or their transformation into the previously non-existent forms. Sociality as such gets "dissolved", as the direct communication between individuals is replaced by virtual communication, a dense layer of constantly circulating information flows, that switch off an individual from the social, from the real relations regarding any activities.

Partly (if not largely) the society ceases to be real, turning into a simulation with the imitation of social processes and events, virtual reality, a conglomerate of signs, not representing the original. J. Baudrillard called this space, forming under the influence of media, the "hyperreality", in which socio-cultural facts lose touch with the objective world and become autonomous simulacra. The relationship of an individual with the world transforms radically in such an era.

Z. Bauman calls the contemporary world the "liquid modernity", "individualized society", society of "postmodernity" [3], which makes human life extremely precarious, fragmented, "elusive" as well as the world itself (A. Giddens calls the postmodern society "elusive", as it is so rapid, it is untraceable by any individual). "Individualization" leads a life of a single human to the ultimate atomization, discontinuity. The process of individualization depends on many external factors not related to the internal needs and desires of a particular person. Individualization is objective, found outside of a person [4. P. 638].

In modern conditions, not only the large-scale social tasks are replaced by personal desires and aspirations, but also the people themselves are more and more willing to abandon long-term plans in favor of short-term episodes (fragments), the sequence of which builds up the human life (but not the personal history, subject to a single consistent logic). In the individualized society, the media execute that much power over the collective and individual imagination of the people.

Z. Bauman also develops enduring insights in his "Liquid Modernity", concerning the former society as the society of "heavy modernity" [5], causing a person to lead the life in a constant stable position. A symbolic manifestation of that modernity was Ford factory with monotonous, simple, mechanical actions that do not involve employees' mental strain. However, people in that society had a fundamentally strong foundation, perspective, protection of the society itself (in the context of the Ford factory, the factory provided for them). Z. Bauman repeatedly uses the symbol of the Fordist factory to characterize "modernity" and then to allocate "postmodernity" as post-Fordist production with a radically different approach to human activity, which, because of its flexibility and dispersion would express the very postmodern era.

The situation of individuals in the "fluid modernity" society, the jobs, to which they can access, opportunities and prospects have been quickly transformed and can no longer serve as a reliable lifegoal. "Blurring", "fragility" of the goals, the sustainable loss of status, uncertainty about the future - this is what distinguishes the individual life of a contemporary individual and society.

Thus, Z. Bauman describes three main features of the "individualized society": "the loss of a human control over the most significant social processes; increasing in this regard uncertainty and progressing insecurity of an individual in the face of the uncontrolled changes; finally, emerging in such conditions the human desire to refuse achieving long-term goals for the sake of immediate results, ultimately leading to the disintegration of both social and individual lives" [6. P. 142].

The British philosopher highlights the changes of the institutions in the coming era of "liquid modernity". $\mathrm{He}$ writes, that nowadays there is almost no institution that can "lead the world forward". Indeed, we have witnessed how the transformation of the social institutions, deinstitutionalization of public life led to deregulation in the management area. The following Z. Bauman's metaphor describes accurately the contemporary social life: "Our life leaves [often enough] an impression that we are just like the passengers on a high-flying plane, found out, that there are no pilots in the cockpit" [7. P. 142].

Self-confidence, the stability of status positions are replaced by a feeling of powerlessness, a state of deep uncertainty and discrete social space, the desire to escape from reality, lack of attention to the current political and social events. However, the growing uncertainty is presented by media as a natural way of existence. A person risks while living a life in this situation of inconsistency and fragmentation of life. Modern society is becoming the "risk society" (U. Beck), but not only in the economic, but also in the mental and cultural senses.

Yet the exit from this situation exists and it is associated not only with the change of the ongoing processes but also with the hope in an individual and the possibility of his diverse identities. An individual himself should identify himself as a citizen, as a member of some ethnic culture, as a part of society, affected by the socio-political transformations. Precisely the possibilities of selfidentification shall be regained by people and thus to terminate the outbreak of "desocialization", "dying out" of social institutions, atomization of personal and public life, elimination of axiological space. Sure, objective social processes transform the mentality of the people, but also the new face of modern society requires the individuals to enter it to a greater extent than it was in the era of "modernity". Let us agree in this respect with the position of A. Giddens, who describes the modern world as a becoming reality, turning the world into a system of more and more open communities, gravitating towards the perception of foreign cultural values and resources. Tourism serves as a positive factor in the transformation of a society in the interaction with the different cultures, and not with the impersonated, but with the personalized ones, connected to specific individuals as the bearers of ethnic and universal values. 


\section{POSTMODERN REFLECTION ON TOURISM}

The French poet, thinker of the late 20th - early 21st century Victor Segalen said once that since we had learned that the Earth is round, the journey ceased to exist, as the withdrawing from a certain point means the approach to the same point. So begins "tourism" - an endless flow of people who, in a strict sense, do not travel, but move in circles in a confined space. There is no more exotics. There is the interaction of cultures, which contributes to the tourism and all the meanings and symbols associated with it.

According to the author of the article, people, as the representatives of diverse cultures, are integrated by tourism in the philosophical sense. Therefore, we shall understand the category "tourism" in the broadest sense. All the movement bring people closer. The circulation gains momentum: knowledge, technology, culture, information, money, communication and economic transactions circulate. J. Baudrillard expresses the following idea: the human Universe has turned into a huge orbital station, "the space era has begun, which space is television" [8. P. 12].

In general, radical changes in the very foundations of the postmodern culture were caused by the transformations of media and communicative forms themselves, replacing the print with digital technology and thus turning the postmodern society into a networked, virtualized one. The Russian sociologist Denis Chistyakov rightly stresses the very essence of mass communication in the postmodern era. He writes: "Social relations in the audiovisual postmodern culture transform into human-machine relations. An individual lives in an imaginary world of screens, interfaces, programs and networks. The screen appears to be a text medium instead of writing, as it was the case in the previous, book culture. Screen culture with its own non-verbal language can perform a "clean offering" of a reality with which an individual may interact without mediators. Such communications are not preceded by the verbalized knowledge so there is no reality transformation caused by language" [9. P. 299].

Let us note that in the new global culture, nowadays called "the screen culture", tourism plays a significant role. The English sociologist J. Urry, the founder of the so-called "sociology of mobility", studying global changes, offers new methods of analyzing economics, tourism, social infrastructure. Considering how people become the global consumers of places, J. Urry in his "The Tourist Gaze and Globalization" claims that "since the beginning of the 1990s, people have experienced the significant "space-time compression", people became closer to each other because of the modern technologies and communications". He writes further: "Many social groups are becoming increasingly aware of the "death of the distance" [10. P. 136]. However, he adheres to the $Z$. Bauman's views that we move from stable to "liquid modernity".

The feeling of the space-time compression arises largely thanks to steady, rapid flows of journeymen, tourists, pilgrims, everyone, included into the orbit of people, moving around the Earth. Yet the postmodern world offers us another kind of journey: to the same places, where people travel to, but virtually. That is why J. Urry categorizes tourism as a journey "in flesh" and the imaginative tourism using Internet, phones, TV and other digital media.

Nowadays the global tourism industry, the fluidity as the defining category of the contemporary communities, have caused the processes of "production" and "consumption" of the places [11]. Relations among communities on the globe, the real relationship among people, lacking due to the abovementioned reasons, are mediated by the flows of tourists. Therefore, the places change, improve, set themselves to accept these flows.

Globalization has made tourism global because here a huge number of places and people gets interconnected. In this regard, "global" and "tourism" are not the separate concepts, connected by some external links, but a part of the complex independent system of interchangeable modern processes. Therefore, the tourism infrastructure, flows of people, generated images of the place visited, the variety of social practices, associated with tourism are comprehended within a "real reflection", which gets institutionalized form; the scholar research of tourism, magazines, newspapers, textbooks, travel agencies, corporations, etc., existing in unity as a global hybrid, spreading across the globe [12].

Tourism, in our view, accumulates all the principles of the postmodern society. Moreover, the established media and beautifully "packaged", for the purpose of advertising, images of tourist sites and facilities spread throughout the world and thereby create and implement the idea of the globe as a single place to visit. It is appropriate to recall the Segalen's idea of the globe as the symbol of tourism. Nowadays the visuality plays more significant role in spreading the ideas of the global tourism than twenty or thirty years ago.

However, there are other varieties of the so-called "tourists", who travel around the world not on their own. J. Urry notes in this regard: "The global tourists and travelers in many "empty meeting places" or "non-places" of contemporaneity, such as the waiting rooms of airports, bus and train stations, highway service stations, ports, etc., are adjoined by the countless exiles from all over the world" [13. P. 138]. These are the "non-places" described by Z. Bauman and occupied by migrants and refugees. Economic, social, sometimes religious reasons are forcing people to become conditional, or forced tourists, whose mobility is not due to the desire to travel. The specific nature of social violence, manifested in the quickening non-linear history development, using of the psychological manipulation of the masses, the inclusion of the interpreted religious ideas with a goal to subordinate communities and groups of people and carrying out of destructive, sometimes military or terrorist acts [14] make people leave their habitats and move, seek new environments, adapt to the new, unfamiliar, sometimes even hostile, socio-cultural conditions. However, the institutionalization of tourism reflection makes tourism almost the center of "liquid modernity", promoting globalization, bringing the cultures closer. The formation of a new tourist destination is the result of long-term work, a part of a reflexive process, through which the new places, previously unknown, get included into a globalized world ("orbital station" - J. Baudrillard). In this regard, many objects, that were not the objects of interest before, are becoming relevant. Tourist infrastructures are being created in the 
most unexpected places, perhaps in order to reproduce the lost exotic. Among those locations are Alaska, Antarctic, Cuba in terms of its "colonial" heritage, Iceland, etc.

The flow of the tourists from different countries increases, especially this concerns the eastern countries as if replacing the Western "consumption of the places" in the East. Moreover, there is the growing desire of the Eastern tourists to see firsthand the places of the West, that, according to the tourists, contributed largely to the development of the world. The American sociologist J. Hendry describes the creation in the Asian countries of the theme parks, that are full of "exotic Western" features. In those parks the oases of the Western culture is cultivated and reproduced. The sociologist call this trend the reverse Orientalism or the Orientalist retaliation [15], when the bizarre (to an Eastern individual) artifacts of the Western civilization are displayed and perceived as unusual, exotics, weird.

Tourism is also important for implementing some existential entities of an individual. The need to realize oneself in a not very comfortable world, the desire to communicate, to shorten distances, to visit in person some mega-events, to experience events, meetings with people, to engage in new spaces - in short, all those existential manifestations, without which no one can live in a harsh and not very friendly modern world, contribute to the development of tourism. Tourism, in turn, enables people to implement their desires and helps in their cultural identification. Getting into an unknown culture with peculiar religious, ethnic, socio-ethical forms of behavior, everyone compares it to the own ethnic culture. All this contributes to the building of cultural identity and those processes in the native society that allow or impede the formation of multiple identifications - as a citizen, as a representative of some subculture or ethnic culture, etc. [16]. That is why the internal motives of a person form largely the global flows of tourists in their quest not only to explore the new places but also to know themselves as parts of an ethnic group, culture, state.

Gravitation to co-presence in a meaningful for an individual place almost always pushes him to travel the unknown spaces, to reach visually different landscapes of life events. Mediated by tourism socio-cultural practices are possible only in specific "leisure places", geographically and ontologically distant from work and home. These are felt as the "other" places, different from the daily routine and familiar sights. New Zealand, e.g., is now developing the extreme "adventure tourism", exhibiting forms of a physical counteraction to battle routine.

\section{CONCLUSION}

Thus, the world is a very complex, sometimes contradictory phenomenon. In this variety of the modern world, this special role belongs to ethnic cultures and traditional religions. Currently, we're in need to establish a civilized dialogue of cultures and religions, supporting the idea of peaceful coexistence of different peoples in the context of globalization. We are convinced that spiritual and communicative foundations of religions may play a significant role even in secular (or post-secular) time. Religion is a special mean of communication and as such, it should be used by a modern society for humanitarian purposes. By means of religion, a huge number of people can communicate, interact and share their moral and spiritual needs and preferences. This anthropological and social fact can unite society and contribute to its development.

Besides, in an era of the global movement of people, tourism represents the most relevant factor of mobility, in which people cross national borders and contribute to the translation of different cultures. Tourism contributes to the understanding of people and countries, aiding in the identification of an individual. After all, it is necessary to understand the other ways of life, traditions, forms of spirituality in order to understand who you are in this complex dynamic world.

Exactly this comprehension of another culture is the factor that at least partially may overcome the fragmentation, atomization of the modern world. Tourist migration coincides naturally with the "liquid" condition of the postmodern world and is therefore seen as a positive stimulus for the development of society: the tourist places are being rearranged willy-nilly, changing the infrastructure of the remote and unexplored regions. "The territory of everyday life is being rebuilt as "tourist" samples, as well as many sections of the environment" [17. P. 150]. The world is thus becoming more civilized. Cultural tourism today is a stimulating factor for the development of the states as it erases all boundaries, contradictions, and misunderstanding.

Let us emphasize that religious and cultural diversity of the modern world, expressed partly in the tourist movement, is not a simulacrum, not an illusory incarnation of something that doesn't exist, but an objectively real process that contributes to the establishment of a civilized human interaction in the global world.

\section{REFERENCES}

[1] Chistyakova O.V. Postmodernism, Christian Patristics, and Values of Peace in the Modern Cultures. (In the Context of Educational Process). // Proceedings of the 2016 International Conference on Arts, Design and Contemporary Education. (ICADCE 2016). Advances in Social Science, Education and Humanities Research. Paris: Atlantis Press, 2016. Volume 64. P. 994-999.

[2] Bauman Z. Liquid Modernity. M.: Piter, 2008.

[3] Bauman Z. The Individualized Society. M.: Logos. 2005

[4] Chistyakova O.V. Philosophical-Anthropological Meanings of Postmodernism: "Mediatizing" Human // Philosophical Anthropological Meanings of Postmodernism: "Mediatizing Human // Proceedings of the 2016 International Conference on Contemporary Education, Social Sciences and Humanities. Paris: Atlantis Press, 2016. Volume 74.

[5] Bauman Z. Liquid Modernity. M.: Piter, 2008.

[6] Inozemtsev V.L. The Fates of the Individualized World. Opening article // Bauman Z. The Individualized Society. M.: Logos. 2005.

[7] Bauman Z. The Individualized Society. M: Logos. 2005.

[8] Baudrillard J. The Transparency of Evil. M.: Dobrosvet, KDU. 2009.

[9] Chistyakov D.I. Social Dimension of Media Space in the Age of Postmodernity in the Context of Objective Knowledge Obtainment // Proceedings of the 2016 International Conference on Arts, Design and Contemporary Education. (ICADCE 2016). Advances in Social Science, Education and Humanities Research. Paris: Atlantis Press, 2016. Volume 64.

[10] Urry J. The Tourist Gaze and Globalization // Mass Culture: Modern Western Research. M.: The Fund for Scholar Research "Pragmatics of culture". 2005 
[11] Urry J. Consuming Places. London: Routledge, 1995.

[12] Urry J. Sociology Beyond Societies: Mobilities for the Twenty-First Century. Series: International Library of Sociology. Publisher: Routledge, 2000. Ch.2.

[13] Urry J. The Tourist Gaze and Globalization // Mass Culture: Modern Western Research. M.: The Fund for Scholar Research "Pragmatics of culture". 2005.

[14] Chistyakova O.V. Violence and Religion as Social Phenomena of Contemporaneity (Philosophical Anthropological Context) // Bulletin of Peoples' Friendship University of Russia. 2015. № 1. P. 116-137.

[15] Hendry J. The Orient Strikes Back. A Global View of Cultural Display. Oxford: Berg, 2000

[16] Chistyakova O.V. Problem of Ethnocultural Politics in the «nationalizing state» // Bulletin of Peoples' Friendship University of Russia. 2010. № 4. P. 5-12.

[17] Urry J. The Tourist Gaze and Globalization // Mass Culture: Modern Western Research. M.: The Fund for Scholar Research "Pragmatics of culture". 2005. 